\title{
Plaque Psoriasis: Understanding Risk Factors of This Inflammatory Skin Pathology
}

\author{
Audrey Bélanger1,2, Catiúscia Padilha de Oliveira1, Maxim Maheux ${ }^{1,2,3}$, Roxane Pouliot1,2* \\ ${ }^{1}$ Centre LOEX de l'Université Laval, Génie Tissulaire et Régénération, LOEX-Centre de Recherche FRQS du CHU, \\ Québec, QC, Canada \\ ${ }^{2}$ Faculté de Pharmacie, Université Laval, Québec, QC, Canada \\ ${ }^{3}$ TransBIOTech, Centre de Recherche et de Transfert en Biotechnologies, Lévis, QC, Canada \\ Email: "roxane.pouliot@pha.ulaval.ca
}

Received 30 October 2015; accepted 6 May 2016; published 9 May 2016

Copyright (C) 2016 by authors and Scientific Research Publishing Inc.

This work is licensed under the Creative Commons Attribution International License (CC BY).

http://creativecommons.org/licenses/by/4.0/

(c) (i) Open Access

\begin{abstract}
Covering the entire human body, the skin is considered to be one of the most important organs, since it is the first line of protection against chemical and biological external agents. Although the skin protects tissues and organs against external aggression, it can still be unbalanced by various skin diseases, such as psoriasis. This non-contagious inflammatory dermatosis is characterized by the occurrence of erythematous lesions of various sizes covered with whitish scales. This scaling of the skin is the result of a rapid renewal of the epidermis, occurring over five to seven days instead of 28 days. Psoriasis vulgaris, or plaque psoriasis, is the most common form of this disease and is therefore commonly referred to by the term "psoriasis". This work is a review of the literature on plaque psoriasis, aiming at a better comprehension of the pathology at the histological level, but also to understand the genetic and environmental factors associated with this inflammatory dermatosis.
\end{abstract}

\section{Keywords}

Plaque Psoriasis, Clinical Phenotypes, Comorbidities, Genotype-Phenotype Correlation, Susceptibility Gene

\section{Introduction}

Psoriasis is a common, chronic inflammatory skin disease affecting $2 \%$ to $3 \%$ of the worldwide population, both men and women [1]. However, although psoriasis occurs worldwide, its prevalence varies considerably in dif-

"Corresponding author.

How to cite this paper: Bélanger, A., Padilha de Oliveira, C., Maheux, M. and Pouliot, R. (2016) Plaque Psoriasis: Understanding Risk Factors of This Inflammatory Skin Pathology. Journal of Cosmetics, Dermatological Sciences and Applications, 6, 67-80. http://dx.doi.org/10.4236/jcdsa.2016.62009 
ferent ethnic groups. Indeed, this skin disease is more frequent in Caucasians, while it affects only $0.3 \%$ of the Chinese population [2]. Several forms of psoriasis have been identified and classified into 5 different types: guttate, pustular, erythrodermic, inverse psoriasis and plaque psoriasis (Figure 1) [3]. The latter form, also known as Psoriasis vulgaris, is the commonest form, accounting for up to about $90 \%$ of patients with this disease [4]. Therefore, that type of psoriasis is usually named "psoriasis" and, as the plaque psoriasis is the most predominant form, the majority of studies examining this skin disease are based on this form of psoriasis. This skin pathology is characterized by the presence of erythematous plaques, covered by silvery dry white scales varying in size. In addition, plaque psoriasis vary in severity and may occur only as small and single lesions at localised sites, especially on knees, elbows and the scalp, or be widespread over most of the body and disabling [5]. Beyond the physical appearance, psoriatic lesions are painful and uncomfortable, affecting the life quality of patients and causing various psychosocial problems [6] [7].

Previously, it was thought that psoriasis was caused principally by a disorder in epidermal keratinocytes, leading to their abnormal proliferation and differentiation from epidermal cells [4]. Although the exact cause of this skin disease is still not known, several studies have highlighted the deregulation of the immune system in the development of psoriatic lesions. Indeed, a study has shown the need of immune cells during successful treatment with cyclosporine A, a T cell immunosuppressant [8]. Nowadays, the disease is mainly characterized by hyperkeratosis, parakeratosis, acanthosis, a keratinization disorder where filaggrin and loricrin are under expressed, while involucrin and transglutaminase are over expressed [9]-[11], with leukocyte infiltration and an increased angiogenesis [12] [13] also occurring. In addition, genetic and environmental factors may also play a synergetic role in triggering psoriasis [4] [14]. No curative treatment is currently available to treat the disease; however, there are treatments that can alleviate the symptoms. In this work, our objective is to present a literature review of chronic plaque psoriasis briefly describing the clinical phenotypes of psoriasis, the influence of the genetic and environmental factors and the associated comorbidities.

\section{Clinical Phenotypes of Psoriasis}

Over the decades, the understanding of the disease, although still incomplete, has evolved, and enabled to offer patients a better diagnosis of their psoriasis and, by extension, to offer them the best treatments for their specific type of psoriasis. Although there are no diagnostic criteria for psoriasis, a classification of psoriasis has been proposed to assist practitioners, based on the clinical phenotypes of psoriasis, because it is known today that there are several varieties of clinical occurrence. Indeed, psoriasis, such as described above, can be variable in morphology, distribution and severity. Thereby, this classification of clinical phenotypes relies on various characteristics of psoriasis. Among these are the anatomical sites exposed to lesions, the distribution of the psoriatic

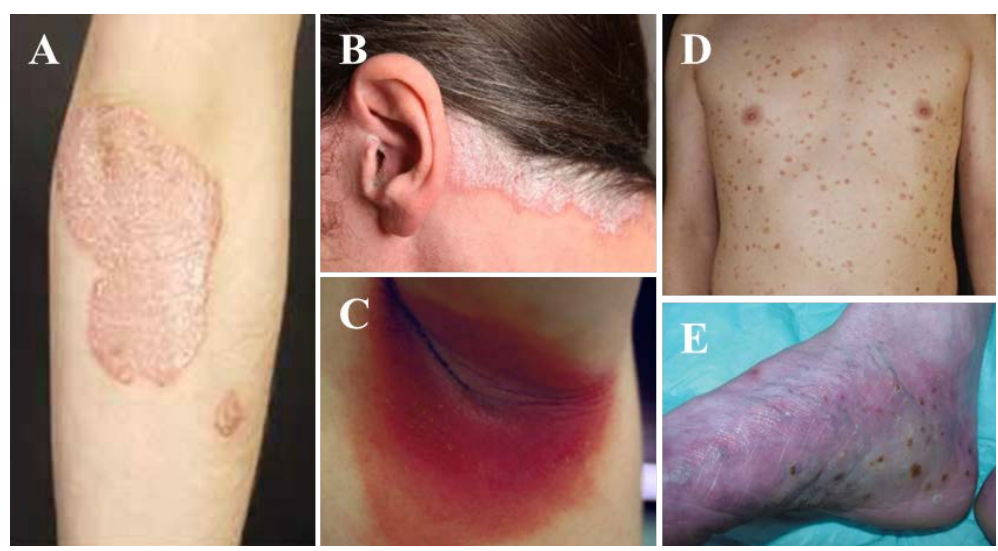

Figure 1. Clinical phenotypes of psoriasis. Plaque psoriasis is characterized by erythematous cutaneous lesions covered by silvery scales, often appearing on the elbow [26] (A). Plaque psoriasis may also develop in the scalp, named seborrheic psoriasis [27] (B). Flexural (inverse) psoriasis is distinguished from others by its reddish plaques without scales located in intertriginous areas [28] (C). Guttate psoriasis [29] (D). Pustular psoriasis (palmoplantar pustulosis) affects the palms and/or soles [30] (E). 
lesions, their thickness and their size and the patient's age [15]-[19]. Moreover, since psoriasis affects psychosocial behavior, it is important to consider the psychological condition of the patient during the diagnosis to maximize the efficiency of the treatment. The various types and presentations of psoriasis are outlined below.

Chronic plaque psoriasis is characterized by well-defined contour plaques, covered with whitish scaly skin, and which are most commonly found on the elbows, knees, lumbosacral area and scalp [20]. Several forms of chronic plaque psoriasis can occur, which are primarily distinguished by size, distribution, and dynamics of psoriatic plaques. Early lesions can appear as small papules, which may become more inflamed and may vary in diameter. Plaque psoriasis may occur as single lesions at predisposed sites or be generalized over the body. Psoriatic lesions can occasionally dominate seborrheic regions and affect areas of the scalp and face such as cheeks, nose, ears, hair line, scalp and interscapular regions [2]. This anatomical distribution of plaque psoriasis is called seborrhoeic psoriasis or sebopsoriasis, since there are many morphological similarities with seborrheic dermatitis [16]. Psoriatic lesions can also be located in the flexural areas, such as the axillae, the inguinal crease, the intergluteal cleft, the inframammary region and the retroauricular folds. When flexural lesions are the only sites of involvement, the term "inverse" psoriasis is sometimes used. This type of psoriasis is distinguished from others by its reddish, shiny, humid thin plaques without scales [21]. Furthermore, plaque psoriasis should be differentiated from other uncommon types of psoriasis such as guttate psoriasis, localized and generalized pustular forms and erythrodermic psoriasis, which are all clinically distinct.

Guttate psoriasis is characterized by small drops of psoriasis over the entire body and no plaque is observed. These psoriatic lesions are located mainly in zones where friction with clothing is involved, such as lower abdomen and lower back, forearms, chest, but also on the scalp and external ear pavilion. Most commonly developed in children or adolescents, guttate psoriasis generally occurs as a result of a $\beta$-haemolytic streptococcal infection, such as tonsillitis, pharyngitis or an upper respiratory tract infection. This acute form of psoriasis often resolves itself, except for some cases that subsequently develop chronic plaque psoriasis [15] [22]. Guttate psoriasis, such as psoriasis vulgaris, has a strong association with the psoriasis susceptibility locus 1, PSORS1, in the major histocompatibility complex region [23]. Genetic predisposition associated with psoriasis vulgaris is discussed in the next section of this review.

Pustular psoriasis is characterized by the presence of pustules on the palms and soles only, in the palmoplantar pustulosis form, or anywhere on the body, in the generalized form [15] [24]. This variant of psoriasis can also progress with plaque psoriasis when the plaques become very inflamed and itchy [16]. Unlike guttate psoriasis, there is no evidence that the three candidate genes at the PSORS1 locus are involved in palmoplantar pustulosis, which appears to be a distinct disorder [23].

Erythrodermic psoriasis is widespread almost all over the body and may be accompanied by severe itching, swelling and pain. It can cause a state of hypothermia, anemia, risk of heart failure or acute respiratory distress syndrome [4] [7]. Erythroderma may be a life threatening condition, and could perhaps be the morphologic presentation of a variety of skin and systemic diseases [25]. Consequently, it is difficult to establish a diagnosis of the underlying disease. The development of erythrodermic psoriasis occurs when there is poor control of an already existing psoriasis, sometimes caused by an abrupt withdrawal of systemic drugs, such as corticosteroids, or in response to a drug such as lithium.

\section{Genetic Predisposition}

A knowledge of the genetic involvement in plaque psoriasis is essential in understanding the disease as well as developing effective treatments. The genetic predisposition is one factor that is known to initiate the characteristic lesions of plaque psoriasis, but is not the only one, as in fact, some psoriasis patients do not present any genetic influence. The genetic predisposition was evidenced by cases involving monozygotic twins and dizygotic twins [31]-[33], but the accurate etiology and the precise role of the genes in the pathogenesis remains unclear. Because genes play a key role in the psoriatic skin disease, understanding the correlation between the genotype-phenotype and the psoriasis susceptibility loci is essential for developing leads to new therapeutic options.

\subsection{Genes Can Trigger Psoriasis-Psoriasis Susceptibility Loci}

The patient's genetic background influences around 35\% - 50\% of the psoriasis heritability, and the PSORS1 and PSORS2 are the principal locus involved [11] [34]. There are three genes in the PSORS1 locus associated with plaque psoriasis. The first one, the HLA-C, is a variation of HLA-Cw6, responsible for the codification of 
MHC first class protein [35] [36]. The other two are the CCHCR1, a coiled-coil $\alpha$ helical rod protein 1and the CDSN, five variant alleles that encode the over expressed protein corneodesmosin. However, 36 genetic loci linked to the occurrence of psoriasis have already been identified, 21 of which are associated with European ancestry. In a recent study, 15 psoriasis-associated regions were identified that are involved in pathway immune mechanisms and show up regulated genes and down regulated genes [37].

The pro-inflammatory genes, genes encoding interleukin (IL)-12, IFN-c, and IFN-c-regulated chemokines or inflammatory mediators also influence the plaque psoriasis and can affect severity of the skin disease [38] [39]. The single-nucleotide polymorphisms (SNPs) and many genes are already associated with plaque psoriasis, such as IL-23R, IL-23A, IL-12B, LCE (late cornified envelope), HLA-Cw*-0602, ZNF313 (zinc-finger protein 313), TNFAIP3 (tumor necrosis factor $\alpha$ induced protein 3) [28], RNF114 (ring finger protein 114), TRAF3IP2 (TNF receptor-associated factor 3 interacting protein 2) and others. Genes expressed in keratinocytes were also identified in plaque psoriasis as LCE3B and LCE3C1 (late cornified envelope 3B and 3C1, respectively) [34]. In a comparison between lesional and non-lesional skins of plaque psoriasis patients, deregulation was observed in the expression of 23 genes [29]. It was also demonstrated that the genes IL-19, IL-20 and IL-24 affect plaque psoriasis, providing a protective effect to haplotypes CAAAC, TGGGT and CGAGT (IL-20/IL-24) [40] and an inductive effect in to haplotype CACCGGAA (IL-19/IL-20) [41].

Since recent progress has been made related to genes and psoriasis susceptibility, many studies have focused on identifying genes that may help decrease the psoriatic plaque. Treatments with biologics drugs have demonstrated gene inhibition, as Adalimumab normalized the genes for innate immunity and epidermal compartment [42], while it was shown in a randomized study that Guselkumab reduced the psoriasis gene expression in patients [43]. Etanercept decreases the IL-17A genes expression [44] and a similar result was observed in patients after treatment with Brodalumab. In this latter case, the genes IL-17A and IL-17C were also down regulated, while IL-17F, responsible for the IL-17 regulation, demonstrated to be dose-dependent with the treatment [45].

\subsection{Genotype-Phenotype Correlations}

It is important to establish correlations between clinical observations and gene expression to understand the genetic risk factors of plaque psoriasis. Several studies have been conducted that have already identified the influence of IFIH1, which encodes the interferon-induced with helicase C domain 1 [46], whereas ERAP1, responsible for the codification of one amino peptidase, regulates the quality of peptides bound to MHC class I molecules, such as HLA-C*06 [47]. The HLA-CW6 is associated with psoriasis development before 40 years of age [48] [49] and with high prevalence in British population [50]. In the IL-12B gene, some SNP has been associated with susceptibility of plaque psoriasis development and with the production of IL-12 and IL-23 in individuals of different ethnic groups [51] [52], including North American Caucasian, European and Asiatic [53]-[56].

One study included 151 psoriasis pediatric patients and 451 healthy controls, all of European descent with a primary diagnosis of plaque-type psoriasis before the age of 18 years. No significant phenotype variations between patients of different ages were found, but a correlation was identified between the genes IFIH1 and ERAP1 and the severity of the disease [57]. Another study performed in Mexican Mestizo population from western Mexico showed that there is no correlation between the SNPrs3212227 (identified in the IL-12B gene), the susceptibility to develop plaque psoriasis and levels of IL-12 and IL-23 in serum [58]. The age and the sex of the patients have no significant influence in genetic aspects of the plaque psoriasis [50]. In China, the SNP rs72474224 in GJB2 is reported as genetic susceptibility to plaque psoriasis and might contribute to the complexity of the disease [59] as well as the polymorphism rs6887695 of the IL-12B gene [60]. In contradiction with the study of Oostveen et al. [57], Hébert et al. found eight loci associated with early-onset psoriasis, HLA-C, IL-12B, TRAF3IP2, IL-23R, RNF114, IFIH1, IL-23A and HLA-A [61]. Indeed, the influence of HLA-C and IL-12B had already been described in a previous study [37] [62].

Several studies have focused on the genes involved in the onset of psoriasis before 40 years. However, the genetic influence on plaque psoriasis can also be present in the late onset psoriasis as demonstrated by Hébert et al., suggesting that the late onset of psoriasis can be a type of plaque psoriasis [61]. Besides the influence in the disease onset, the genes can also be involved in the thickness of the plaque psoriasis [29] [63], including the genetic expression of IL-22, IL-19 and LCN2 in non-lesional skin of the thick plaque psoriasis patients [29]. Furthermore, one recent study evidenced the correlation between the C677T polymorphism in the methylenetetrahydrofolate reductase polymorphism and plaque psoriasis severity [64], corroborating the study of the Baiqiu et 
al. [65].

In summary, the pathway to elucidate the factors triggering plaque psoriasis involves knowledge of the genetic contribution. Accurate genetic influence in plaque psoriasis is not completely understood but is well documented, and many advances have already been achieved. However, more studies exploring that relationship are necessary to fully elucidate genetic involvement in plaque psoriasis.

\section{Environmental Factors in the Psoriasis Pathology}

Although the exact causes of psoriasis are not fully understood, it is widely accepted that environmental factors and genetic predisposition act jointly to lead to the development of the disease. Many environmental risk factors, such as smoking habits, extreme temperature, drug reaction, stress and infections, appear to be able to trigger or exacerbate the disease [66] and are discussed below (Figure 2).

Smoking is a leading lifestyle factor that affects human health and can influence the development of psoriasis, since smoke has an important extra-pulmonary toxicity [67]. Epidemiologic studies have pointed to a strong association between psoriasis and current smokers, and between psoriasis and former smokers [68]. Psoriasis is a $\mathrm{T}$ cell immune-mediated disease and nicotine alters a wide range of immunological functions, including innate and adaptive immune responses [69] [70]. In fact, according to the literature, nicotine consumption results in an increased secretion of IL-12 and numerous other pro-inflammatory cytokines involved in pathologies, such as tumor necrosis factor [71]. Nicotine present in tobacco also causes dysregulated expression of vascular endothelial growth factor, an important factor in angiogenesis. Since psoriasis is characterized by an increase in angiogenesis [12], this could partly explain the relationship between smoking and psoriasis. The influence of long-term smoke exposure on the development of psoriasis also stems from the fact that smoking induces oxidative stress and free radical damage [67]. The increased presence of free radicals in the human body has the potential to trigger a cascade of systemic effects, including the development of psoriasis.

Psychological or emotional stress is one of the main reasons for the exacerbation of psoriasis patients [72]. Indeed, psychological stressors might contribute to the severity of chronic inflammatory diseases such as psoriasis by dysregulating hypothalamic-pituitary-adrenal (HPA) axis activity, where the body begins to secrete the hormone cortisone, which affects the epidermal barrier and increases the secretion of pro-inflammatory cytokines [73] [74]. Besides the psychological stress, the body may suffer physical stress trauma to the skin, like sunburn or scratches. This physical trauma can trigger psoriasis patients in the Koebner phenomenon, a phenomenon characterized by the appearance of psoriasis after skin trauma, ahead of exacerbation of psoriasis [75] [76].

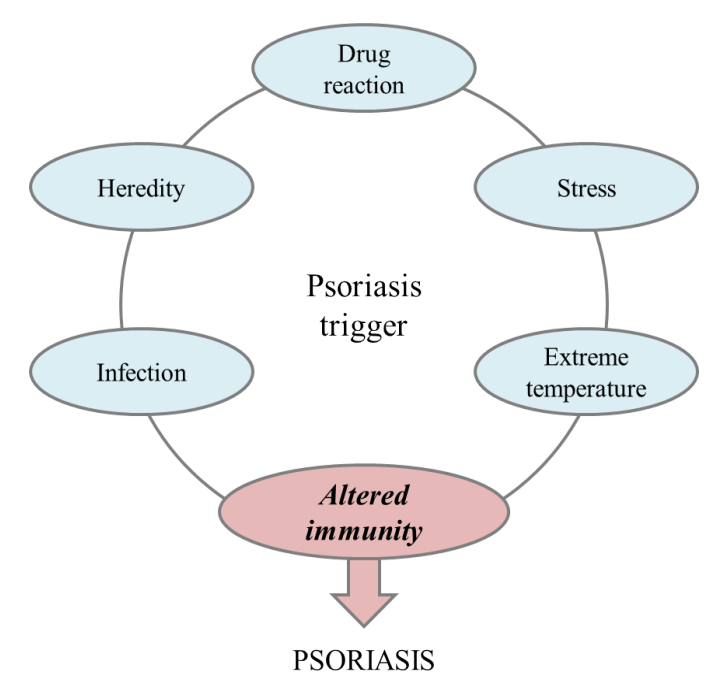

Figure 2. Various causative factors could influence the development of psoriasis. Environmental factors such as extreme temperature, infection, stress or smoking and genetic predisposition act jointly to lead to the development of psoriasis. 
The development of plaque psoriasis can also be affected by seasonal variation. In fact, psoriasis worsens in winter, because the temperature of this cold season causes a low level of humidity, which in turn may increase skin permeability, induce thickening of the epidermis and stimulate the production of inflammatory mediators [77].

Furthermore, certain drugs are known for inciting or exacerbating triggers of psoriasis. Indeed, drugs like lithium and beta-blockers can trigger psoriasis, while antimalarial drugs such as chloroquine or hydroxychloroquine may exacerbate it [78]. Lithium and beta-blockers decrease the level of cyclic adenosine monophosphate (cAMP) in keratinocytes, thus leading to an increased proliferation and decreased differentiation [79], as chloroquine or hydroxychloroquine inhibit transglutaminase in the epidermis, an important enzyme in the formation of the epidermis [80].

Microbial infections may also exacerbate pre-existing chronic plaque psoriasis, in addition to being responsible for the onset of disease in normal subjects. Streptococcus pyogenes ( $\beta$-hemolytic) infections were strongly associated with the initiation of guttate psoriasis [81] while Staphylococcus aureus or yeast such as Candida albicans have been reported as being responsible for the worsening of psoriatic lesions [78]. These three microorganisms have similar mechanisms of action involving all superantigens capable of activating $\mathrm{T}$ cells [82].

\section{Comorbidity}

Psoriasis patients are known to have an elevated risk of developing comorbidities such as cardiovascular diseases, metabolic syndromes, and others [83]-[86]. The high presence of the pro-inflammatory cytokines, as for example, the TNF, interleukins, IFN- $\gamma$, and C-reactive protein, can contribute to initiation of other diseases by the deregulated trafficking of the immune cells, and can be released into the systemic circulation modifying the function of the cells in different organs [87]. Plaque psoriasis treatments can contribute to attenuate risk of comorbidities or can further increase the risk. The TNF-alfa antagonists are associated with the decrease of liver comorbidities and arthropathies [88] [89], however these are also related to weight gain in patients [90] and infectious diseases [91]. Furthermore, methotrexate use is associated with reduced risks of cardiovascular diseases in comparison to non-treated patients [92], but is associated with hyperhomocysteinemia and liver fibrosis [93].

\subsection{Cardiovascular Disease}

Psoriasis patients have about a 25\% increased relative risk of cardiovascular diseases [94] and have related risks for arterial stiffness [95], vascular damage, atherogenesis [84], myocardial infarction and coronary artery calcification [96] [97]. In fact, coronary disease is the most common cardiovascular comorbidity associated with psoriasis [97] [98]. Studies conducted on plaque psoriasis, with adults and children, have demonstrated the high prevalence of the relationship between plaque psoriasis and cardiovascular disease. Torres et al. conducted a case-control study on children that showed an increase in atherogenic factors related to the risk of cardiovascular diseases [99]. In addition, high levels of cytokines in the blood stream, such as TNF- $\alpha$, IL-2, IL-17 and IFN- $\gamma$, combined with altered angiogenesis and endothelial functions were studied as a possible cause of cardiovascular diseases [100] [101] and accelerated atherosclerosis [102], which is a situation present in plaque psoriasis. In one case-control study, Arias-Santiago et al. found four times more carotid atheroma plaques in psoriatic patients than in controls [103]. Votrubova et al. in a study conducted with 131 patients with chronic plaque psoriasis and 267 control patients with other skin disorders, observed relationships between psoriasis and risk factors for cardiovascular diseases such as hypertension, higher body mass index and reduced HDL cholesterol levels [104].

Since psoriasis can initiate a cardiovascular disorder, with altered risk factors, treatments alleviating plaque psoriasis may be useful for reducing those risk factors, as shown by Boehncke et al. [105]. After fumaric acid ester treatment, patients with clinical insulin resistance returned to normal levels, and the high-sensitive CRP serum and vascular endothelial growth factor levels were reduced, causing the improvement of endothelial cell function in patients with moderate-to-severe psoriasis vulgaris.

\subsection{Metabolic Syndrome}

Metabolic syndrome includes different conditions such as obesity, dyslipidemia, diabetes and hypertension [106]. In obese patients, the occurrence of these conditions is twice as frequent when the patients have psoriasis in comparison to patients without psoriasis or with other skin diseases [107]. This fact was confirmed in the 
study of Akcali et al. [108], where hypertension was more frequent in patients with psoriasis than in controls. Furthermore, Rajappa et al. [83] showed the increase of pro-inflammatory adipokines, insulin levels and insulin resistance indices and the decrease of anti-inflammatory adipokines, adiponectin and insulin sensitivity indices in psoriatic patients in comparison with controls.

The exact mechanism involved when psoriatic patients develop another related disease is not completely understood, but genetic and environmental factors and inflammatory components are probable causes. The overproduction of pro-inflammatory cytokines, with persistent secretion of TNF- $\alpha$, IL-1, IL-6 and others, can contribute to chronic inflammation and development of metabolic disorders [109] [110]. The high pro-inflammatory mediator levels in the pathogenesis of psoriasis are also responsible for the metabolic syndromes. In the case of obesity as comorbidity, for example, that dysregulation can increase the production of leptin, visfatin, resistin, IL-6 and a decrease in the anti-inflammatory adipokines with insulin-sensitizing properties levels [111] [112] and consequently, initiation of the disease.

Treatment of psoriasis with acitretin, ciclosporin and TNF- $\alpha$ antagonists can contribute to the development of comorbidities by the increase of serum lipid levels [113], by the increase of serum uric acid and the development of dyslipidaemia [114] and by a weight gain induced by these drugs [90]. Besides, treatment with methotrexate helps to decrease the adipokines levels in psoriatic patients by anti-inflammatory action [83]. Though the TNF- $\alpha$ antagonists possibly contribute to weight gain, studies also indicated that those drugs can help to reduce the intima-media thickness, an indicator of atherosclerosis [54].

\subsection{Coagulation Disorders}

The influence of the psoriasis in platelet activation has also been studied. The platelets are responsible for hemostasis support, and deregulation can cause several cardiovascular diseases, such as atherosclerosis, coronary vascular disease and cerebrovascular disease [115]-[117]. It has been shown, in plaque psoriasis patients, that platelets tend to aggregate and consequently cause occlusive vascular disease [115] [116]. Several platelet indices are altered in psoriatic patients, such as mean platelet volume, higher reactivity when put in contact with adenosine diphosphate, collagen and thrombin [118]. Psoriasis can initiate an increase in the concentrations of the inflammatory markers [116] [119] and the platelet activation can initiate another disorders [116] [120].

\subsection{Other Inflammatory Disease}

Psoriatic patients have high risk of some cancers, such as lymphoma and non-melanoma skin cancer [121] [122]. The increased risk of those diseases can be associated with the physiology of the disease or its treatment. With severe plaque psoriasis, the patients taking antitumoral and immunosupressor drugs, besides the PUVA treatment, present an increased risk of tumor development [123]. Dental problems, such as periodontitis and radiographic bone loss, are other disorders that plaque psoriasis patients may develop with a higher risk than the general population [124]. Other studies have identified, in some patients, hyperuricemia, high serum uric acid and chronic kidney disease as consequences of psoriasis [125]. These cases can arise from the pathology or from the treatment, as for example, the use of nonsteroidal anti-inflammatory drugs, which is strongly linked with kidney problems [125].

\section{Conclusion}

Psoriasis is a chronic skin disorder characterized by erythematous plaque with silvery white scales. The scaly red plaque is a clinical reflection of hyperkeratosis, parakeratosis, acanthosis of the epidermis, dilated vessels, and an inflammatory infiltrate composed primarily of lymphocytes. Skin lesions may be on specific anatomic sites, such as elbows or knees, or on the entire skin surface. Although the characteristics of psoriasis are well documented, the cause of the disease remains unknown. However, two main factors that affect the onset and exacerbation of the disease have been reported: environmental factors and genetic predisposition. Both factors would act jointly in triggering the disease. This skin disease can appear at any age, but two peaks in age of onset have been reported: one at 20 - 30 years and a second at 50 - 60 years. In approximately $75 \%$ of the occurrences, the onset is before 40 years old, where the HLA-CW6 is associated. People with psoriasis are at an elevated risk of developing other chronic and serious health conditions, also known as "comorbidities", such as cardiovascular disease, metabolic syndrome (obesity, dyslipidemia, diabetes and hypertension) and coagulation disorders. 


\section{References}

[1] Raychaudhuri, S.P. and Farber, E.M. (2001) The Prevalence of Psoriasis in the World. Journal of the European Academy of Dermatology and Venereology, 15, 16-17. http://dx.doi.org/10.1046/j.1468-3083.2001.00192.x

[2] Griffiths, C.E., Christophers, E., Barker, J.N., Chalmers, R.J., Chimenti, S., Krueger, G.G., Leonardi, C., Menter, A., Ortonne, J.P. and Fry, L. (2007) A Classification of Psoriasis Vulgaris According to Phenotype. British Journal of Dermatology, 156, 258-262. http://dx.doi.org/10.1111/j.1365-2133.2006.07675.x

[3] Wu, W., Debbaneh, M., Moslehi, H., Koo, J. and Liao, W. (2014) Tonsillectomy as a Treatment for Psoriasis: A Review. The Journal of Dermatological Treatment, 25, 482-486. http://dx.doi.org/10.3109/09546634.2013.848258

[4] Griffiths, C.E. and Barker, J.N. (2007) Pathogenesis and Clinical Features of Psoriasis. Lancet, 370, $263-271$. http://dx.doi.org/10.1016/S0140-6736(07)61128-3

[5] Nestle, F.O., Kaplan, D.H. and Barker, J. (2009) Psoriasis. New England Journal of Medicine, 361, 496-509. http://dx.doi.org/10.1056/NEJMra0804595

[6] Wahl, A.K., Gjengedal, E. and Hanestad, B.R. (2002) The Bodily Suffering of Living with Severe Psoriasis: In-Depth Interviews with 22 Hospitalized Patients with Psoriasis. Qualitative Health Research, 12, 250-261. http://dx.doi.org/10.1177/104973202129119874

[7] Langley, R.G., Krueger, G.G. and Griffiths, C.E. (2005) Psoriasis: Epidemiology, Clinical Features, and Quality of Life. Annals of the Rheumatic Diseases, 64, ii18-23; Discussion ii24-15. http://dx.doi.org/10.1136/ard.2004.033217

[8] Powles, A.V., Baker, B.S., Valdimarsson, H., Hulme, B. and Fry, L. (1990) Four Years of Experience with Cyclosporin A for Psoriasis. British Journal of Dermatology, 122, 13-19. http://dx.doi.org/10.1111/j.1365-2133.1990.tb02877.x

[9] McKay, I.A. and Leigh, I.M. (1995) Altered Keratinocyte Growth and Differentiation in Psoriasis. Clinics in Dermatology, 13, 105-114. http://dx.doi.org/10.1016/0738-081X(95)93817-8

[10] Bernard, B.A., Asselineau, D., Schaffar-Deshayes, L. and Darmon, M.Y. (1988) Abnormal Sequence of Expression of Differentiation Markers in Psoriatic Epidermis: Inversion of Two Steps in the Differentiation Program? The Journal of Investigative Dermatology, 90, 801-805. http://dx.doi.org/10.1111/1523-1747.ep12462014

[11] Giardina, E., Capon, F., De Rosa, M.C., Mango, R., Zambruno, G., Orecchia, A., Chimenti, S., Giardina, B. and Novelli, G. (2004) Characterization of the Loricrin (LOR) Gene as a Positional Candidate for the PSORS4 Psoriasis Susceptibility Locus. Annals of Human Genetics, 68, 639-645. http://dx.doi.org/10.1046/j.1529-8817.2004.00118.x

[12] Heidenreich, R., Rocken, M. and Ghoreschi, K. (2009) Angiogenesis Drives Psoriasis Pathogenesis. International Journal of Experimental Pathology, 90, 232-248. http://dx.doi.org/10.1111/j.1365-2613.2009.00669.x

[13] Gaspari, A.A. (2006) Innate and Adaptive Immunity and the Pathophysiology of Psoriasis. Journal of the American Academy of Dermatology, 54, S67-S80. http://dx.doi.org/10.1016/j.jaad.2005.10.057

[14] Ortonne, J.-P. (1996) Aetiology and Pathogenesis of Psoriasis. British Journal of Dermatology, 135, 1-5. http://dx.doi.org/10.1111/j.1365-2133.1996.tb15660.x

[15] Raychaudhuri, S.K., Maverakis, E. and Raychaudhuri, S.P. (2014) Diagnosis and Classification of Psoriasis. Autoimmunity Reviews, 13, 490-495. http://dx.doi.org/10.1016/j.autrev.2014.01.008

[16] Naldi, L. and Gambini, D. (2007) The Clinical Spectrum of Psoriasis. Clinics in Dermatology, 25, 510-518. http://dx.doi.org/10.1016/j.clindermatol.2007.08.003

[17] Henseler, T. and Christophers, E. (1985) Psoriasis of Early and Late Onset: Characterization of Two Types of Psoriasis Vulgaris. Journal of the American Academy of Dermatology, 13, 450-456. http://dx.doi.org/10.1016/S0190-9622(85)70188-0

[18] Pariser, D.M., Bagel, J., Gelfand, J.M., Korman, N.J., Ritchlin, C.T., Strober, B.E., Van Voorhees, A.S., Young, M., Rittenberg, S., Lebwohl, M.G. and Horn, E.J. (2007) National Psoriasis Foundation Clinical Consensus on Disease Severity. Archives of Dermatology, 143, 239-242. http://dx.doi.org/10.1001/archderm.143.2.239

[19] Raychaudhuri, S.P. and Gross, J. (2000) A Comparative Study of Pediatric Onset Psoriasis with Adult Onset Psoriasis. Pediatric Dermatology, 17, 174-178.

[20] Griffiths, C.E. and Barker, J.N. (2007) Pathogenesis and Clinical Features of Psoriasis. The Lancet, 370, $263-271$. http://dx.doi.org/10.1016/S0140-6736(07)61128-3

[21] Ayala, F. (2007) Clinical Presentation of Psoriasis. Reumatismo, 59, 40-45.

[22] Naldi, L., Peli, L., Parazzini, F. and Carrel, C.F. (2001) Family History of Psoriasis, Stressful Life Events, and Recent Infectious Disease Are Risk Factors for a First Episode of Acute Guttate Psoriasis: Results of A Case-Control Study. Journal of the American Academy of Dermatology, 44, 433-438. http://dx.doi.org/10.1067/mjd.2001.110876

[23] Asumalahti, K., Ameen, M., Suomela, S., Hagforsen, E., Michaelsson, G., Evans, J., Munro, M., Veal, C., Allen, M., 
Leman, J., Burden, A.D., Kirby, B., Connolly, M., Griffiths, C.E., Trembath, R.C., Kere, J., Saarialho-Kere, U. and Barker, J.N. (2003) Genetic Analysis of PSORS1 Distinguishes Guttate Psoriasis and Palmoplantar Pustulosis. The Journal of Investigative Dermatology, 120, 627-632. http://dx.doi.org/10.1046/j.1523-1747.2003.12094.x

[24] Weigle, N. and McBane, S. (2013) Psoriasis. American Family Physician, 87, 626-633.

[25] Balasubramaniam, P. and Berth-Jones, J. (2004) Erythroderma: 90\% Skin Failure. Hospital Medicine, 65, $100-102$.

[26] Schon, M.P. and Boehncke, W.H. (2005) Psoriasis. The New England Journal of Medicine, 352, 1899-1912. http://dx.doi.org/10.1056/NEJMra041320

[27] Chong, H.T., Kopecki, Z. and Cowin, A.J. (2013) Lifting the Silver Flakes: The Pathogenesis and Management of Chronic Plaque Psoriasis. BioMed Research International, 2013, Article ID: 168321. http://dx.doi.org/10.1155/2013/168321

[28] Roberson, E.D. and Bowcock, A.M. (2010) Psoriasis Genetics: Breaking the Barrier. Trends in Genetics, 26, $415-423$. http://dx.doi.org/10.1016/j.tig.2010.06.006

[29] Kim, B.Y., Choi, J.W., Kim, B.R. and Youn, S.W. (2015) Histopathological Findings Are Associated with the Clinical Types of Psoriasis but Not with the Corresponding Lesional Psoriasis Severity Index. Annals of Dermatology, 27, 2631. http://dx.doi.org/10.5021/ad.2015.27.1.26

[30] Langley, R., Krueger, G. and Griffiths, C. (2005) Psoriasis: Epidemiology, Clinical Features, and Quality of Life. Annals of the Rheumatic Diseases, 64, ii18-ii23. http://dx.doi.org/10.1136/ard.2004.033217

[31] Lonnberg, A.S., Skov, L., Skytthe, A., Kyvik, K.O., Pedersen, O.B. and Thomsen, S.F. (2013) Heritability of Psoriasis in a Large twin Sample. British Journal of Dermatology, 169, 412-416. http://dx.doi.org/10.1111/bjd.12375

[32] Pedersen, O.B., Svendsen, A.J., Ejstrup, L., Skytthe, A. and Junker, P. (2008) On the Heritability of Psoriatic Arthritis. Disease Concordance among Monozygotic and Dizygotic Twins. Annals of the Rheumatic Diseases, 67, 1417-1421. http://dx.doi.org/10.1136/ard.2007.078428

[33] Gervin, K., Vigeland, M.D., Mattingsdal, M., Hammero, M., Nygard, H., Olsen, A.O., Brandt, I., Harris, J.R., Undlien, D.E. and Lyle, R. (2012) DNA Methylation and Gene Expression Changes in Monozygotic Twins Discordant for Psoriasis: Identification of Epigenetically Dysregulated Genes. PLoS Genetics, 8, e1002454. http://dx.doi.org/10.1371/journal.pgen.1002454

[34] Monteleone, G., Pallone, F., MacDonald, T.T., Chimenti, S. and Costanzo, A. (2011) Psoriasis: From Pathogenesis to Novel Therapeutic Approaches. Clinical Science, 120, 1-11.

[35] Lesueur, F., Lefevre, C., Has, C., Guilloud-Bataille, M., Oudot, T., Mahe, E., Lahfa, M., Mansouri, S., Mosharraf-Olmolk, H., Sobel, E., Heath, S., Lathrop, M., Dizier, M.H., Prud'Homme, J.F. and Fischer, J. (2007) Confirmation of Psoriasis Susceptibility Loci on Chromosome 6p21 and 20p13 in French Families. The Journal of Investigative Dermatology, 127, 1403-1409. http://dx.doi.org/10.1038/sj.jid.5700749

[36] Gandhi, G., Buttar, B.S., Albert, L., Hasan, Q. and Aggarwal, R.K. (2011) Psoriasis-Associated Genetic Polymorphism in North Indian Population in the CCHCR1 Gene and in a Genomic Segment Flanking the HLA-C Region. Disease Markers, 31, 361-370. http://dx.doi.org/10.1155/2011/682782

[37] Tsoi, L.C., Spain, S.L., Knight, J., Ellinghaus, E., Stuart, P.E., Capon, F., Ding, J., Li, Y., Tejasvi, T., Gudjonsson, J.E., Kang, H.M., Allen, M.H., McManus, R., Novelli, G., Samuelsson, L., Schalkwijk, J., Stahle, M., Burden, A.D., Smith, C.H., Cork, M.J., Estivill, X., Bowcock, A.M., Krueger, G.G., Weger, W., Worthington, J., Tazi-Ahnini, R., Nestle, F.O., Hayday, A., Hoffmann, P., Winkelmann, J., Wijmenga, C., Langford, C., Edkins, S., Andrews, R., Blackburn, H., Strange, A., Band, G., Pearson, R.D., Vukcevic, D., Spencer, C.C., Deloukas, P., Mrowietz, U., Schreiber, S., Weidinger, S., Koks, S., Kingo, K., Esko, T., Metspalu, A., Lim, H.W., Voorhees, J.J., Weichenthal, M., Wichmann, H.E., Chandran, V., Rosen, C.F., Rahman, P., Gladman, D.D., Griffiths, C.E., Reis, A., Kere, J., Collaborative Association Study of Psoriasis (CASP), Genetic Analysis of Psoriasis Consortium, Psoriasis Association Genetics Extension, Wellcome Trust Case Control Consortium 2, Nair, R.P., Franke, A., Barker, J.N., Abecasis, G.R., Elder, J.T. and Trembath, R.C. (2012) Identification of 15 New Psoriasis Susceptibility Loci Highlights the Role of Innate Immunity. Nature Genetics, 44 1341-1348. http://dx.doi.org/10.1038/ng.2467

[38] Rottman, J.B., Smith, T.L., Ganley, K.G., Kikuchi, T. and Krueger, J.G. (2001) Potential Role of the Chemokine Receptors CXCR3, CCR4, and the Integrin alphaEbeta7 in the Pathogenesis of Psoriasis Vulgaris. Laboratory Investigation, 81, 335-347.

[39] Oestreicher, J.L., Walters, I.B., Kikuchi, T., Gilleaudeau, P., Surette, J., Schwertschlag, U., Dorner, A.J., Krueger, J.G. and Trepicchio, W.L. (2001) Molecular Classification of Psoriasis Disease-Associated Genes through Pharmacogenomic Expression Profiling. The Pharmacogenomics Journal, 1, 272-287. http://dx.doi.org/10.1038/sj.tpj.6500067

[40] Koks, S., Kingo, K., Vabrit, K., Ratsep, R., Karelson, M., Silm, H. and Vasar, E. (2005) Possible Relations between the Polymorphisms of the Cytokines IL-19, IL-20 and IL-24 and Plaque-Type Psoriasis. Genes and Immunity, 6, 407-415. http://dx.doi.org/10.1038/sj.gene.6364216 
[41] Koks, S., Kingo, K., Ratsep, R., Karelson, M., Silm, H. and Vasar, E. (2004) Combined Haplotype Analysis of the Interleukin-19 and -20 Genes: Relationship to Plaque-Type Psoriasis. Genes and Immunity, 5, 662-667. http://dx.doi.org/10.1038/sj.gene.6364141

[42] Hendriks, A.G., van der Velden, H.M., Wolberink, E.A., Seyger, M.M., Schalkwijk, J., Zeeuwen, P.L., de Jong, E.M., Pasch, M.C., van Erp, P.E. and van de Kerkhof, P.C. (2014) The Effect of Adalimumab on Key Drivers in the Pathogenesis of Psoriasis. British Journal of Dermatology, 170, 571-580. http://dx.doi.org/10.1111/bjd.12705

[43] Sofen, H., Smith, S., Matheson, R.T., Leonardi, C.L., Calderon, C., Brodmerkel, C., Li, K., Campbell, K., Marciniak Jr., S.J., Wasfi, Y., Wang, Y., Szapary, P. and Krueger, J.G. (2014) Guselkumab (an IL-23-Specific mAb) Demonstrates Clinical and Molecular Response in Patients with Moderate-to-Severe Psoriasis. The Journal of Allergy and Clinical Immunology, 133, 1032-1040. http://dx.doi.org/10.1016/j.jaci.2014.01.025

[44] Johnston, A., Guzman, A.M., Swindell, W.R., Wang, F., Kang, S. and Gudjonsson, J.E. (2014) Early Tissue Responses in Psoriasis to the Antitumour Necrosis Factor-Alpha Biologic Etanercept Suggest Reduced Interleukin-17 Receptor Expression and Signalling. British Journal of Dermatology, 171, 97-107. http://dx.doi.org/10.1111/bjd.12937

[45] Russell, C.B., Rand, H., Bigler, J., Kerkof, K., Timour, M., Bautista, E., Krueger, J.G., Salinger, D.H., Welcher, A.A. and Martin, D.A. (2014) Gene Expression Profiles Normalized in Psoriatic Skin by Treatment with Brodalumab, a Human Anti-IL-17 Receptor Monoclonal Antibody. Journal of Immunology, 192, 3828-3836.

[46] Nejentsev, S., Walker, N., Riches, D., Egholm, M. and Todd, J.A. (2009) Rare Variants of IFIH1, a Gene Implicated in Antiviral Responses, Protect against Type 1 Diabetes. Science, 324, 387-389. http://dx.doi.org/10.1126/science.1167728

[47] York, I.A., Chang, S.C., Saric, T., Keys, J.A., Favreau, J.M., Goldberg, A.L. and Rock, K.L. (2002) The ER Aminopeptidase ERAP1 Enhances or Limits Antigen Presentation by Trimming Epitopes to 8 - 9 Residues. Nature Immunology, 3, 1177-1184. http://dx.doi.org/10.1038/ni860

[48] Levine, D. and Gottlieb, A. (2009) Evaluation and Management of Psoriasis: An Internist’s Guide. The Medical Clinics of North America, 93, 1291-1303. http://dx.doi.org/10.1016/j.mcna.2009.08.003

[49] Patel, R.V., Shelling, M.L., Prodanovich, S., Federman, D.G. and Kirsner, R.S. (2011) Psoriasis and Vascular DiseaseRisk Factors and Outcomes: A Systematic Review of the Literature. Journal of General Internal Medicine, 26, 10361049. http://dx.doi.org/10.1007/s11606-011-1698-5

[50] Prieto-Perez, R., Solano-Lopez, G., Cabaleiro, T., Roman, M., Ochoa, D., Talegon, M., Baniandres, O., Lopez Estebaranz, J.L., de la Cueva, P., Dauden, E. and Abad-Santos, F. (2015) The Polymorphism rs763780 in the IL-17F Gene Is Associated with Response to Biological Drugs in Patients with Psoriasis. Pharmacogenomics, 16, 1723-1731. http://dx.doi.org/10.2217/pgs.15.107

[51] Oppmann, B., Lesley, R., Blom, B., Timans, J.C., Xu, Y., Hunte, B., Vega, F., Yu, N., Wang, J., Singh, K., Zonin, F., Vaisberg, E., Churakova, T., Liu, M., Gorman, D., Wagner, J., Zurawski, S., Liu, Y., Abrams, J.S., Moore, K.W., Rennick, D., de Waal-Malefyt, R., Hannum, C., Bazan, J.F and Kastelein, R.A. (2000) Novel p19 Protein Engages IL-12p40 to Form a Cytokine, IL-23, with Biological Activities Similar as Well as Distinct from IL-12. Immunity, 13, 715-725. http://dx.doi.org/10.1016/S1074-7613(00)00070-4

[52] Cargill, M., Schrodi, S.J., Chang, M., Garcia, V.E., Brandon, R., Callis, K.P., Matsunami, N., Ardlie, K.G., Civello, D., Catanese, J.J., Leong, D.U., Panko, J.M., McAllister, L.B., Hansen, C.B., Papenfuss, J., Prescott, S.M., White, T.J., Leppert, M.F., Krueger, G.G. and Begovich, A.B. (2007) A Large-Scale Genetic Association Study Confirms IL12B and Leads to the Identification of IL23R as Psoriasis-Risk Genes. American Journal of Human Genetics, 80, 273-290. http://dx.doi.org/10.1086/511051

[53] Li, B., Tsoi, L.C., Swindell, W.R., Gudjonsson, J.E., Tejasvi, T., Johnston, A., Ding, J., Stuart, P.E., Xing, X., Kochkodan, J.J., Voorhees, J.J., Kang, H.M., Nair, R.P., Abecasis, G.R. and Elder, J.T. (2014) Transcriptome Analysis of Psoriasis in a large Case-Control Sample: RNA-seq Provides Insights into Disease Mechanisms. The Journal of Investigative Dermatology, 134, 1828-1838. http://dx.doi.org/10.1038/jid.2014.28

[54] Jokai, H., Szakonyi, J., Kontar, O., Marschalko, M., Szalai, K., Karpati, S. and Hollo, P. (2013) Impact of Effective tumor Necrosis Factor-alfa Inhibitor Treatment on Arterial Intima-Media Thickness in Psoriasis: Results of a Pilot Study. Journal of the American Academy of Dermatology, 69, 523-529. http://dx.doi.org/10.1016/j.jaad.2013.06.019

[55] Eiris, N., Santos-Juanes, J., Coto-Segura, P., Gomez, J., Alvarez, V., Morales, B., Queiro, R., Diaz, M., Corao, A.I., Lopez-Corte, K. and Coto, E. (2012) Resequencing of the IL12B Gene in Psoriasis Patients with the rs6887695/ rs3212227 risk Genotypes. Cytokine, 60, 27-29. http://dx.doi.org/10.1016/j.cyto.2012.05.030

[56] Johnston, A., Xing, X., Swindell, W.R., Kochkodan, J., Riblett, M., Nair, R.P., Stuart, P.E., Ding, J., Voorhees, J.J., Elder, J.T. and Gudjonsson, J.E. (2013) Susceptibility-Associated Genetic Variation at IL12B Enhances Th1 Polarization in Psoriasis. Human Molecular Genetics, 22, 1807-1815. http://dx.doi.org/10.1093/hmg/ddt034

[57] Oostveen, A.M., Bergboer, J.G., van de Kerkhof, P.C., Zeeuwen, P.L., de Jong, E.M., Schalkwijk, J. and Seyger, M.M. (2014) Genotype-Phenotype Correlations in a Prospective Cohort Study of Paediatric Plaque Psoriasis: Lack of Corre- 
lation between HLA-C*06 and Family History of Psoriasis. Acta Dermato-Venereologica, 94, 667-671. http://dx.doi.org/10.2340/00015555-1810

[58] Sandoval-Talamantes, A.K., Brito-Luna, M.J., Fafutis-Morris, M., Villanueva-Quintero, D.G., Graciano-Machuca, O., Ramirez-Duenas, M.G. and Alvarado-Navarro, A. (2015) The 3’UTR 1188A/C Polymorphism of IL-12p40 Is Not Associated with Susceptibility for Developing Plaque Psoriasis in Mestizo Population from Western Mexico. Immunology Letters, 163, 221-226. http://dx.doi.org/10.1016/j.imlet.2014.10.004

[59] Yao, F., Yue, M., Zhang, C., Zuo, X., Zheng, X., Zhang, A., Wang, Z., Liu, S., Li, H., Meng, L., Zeng, M., Fan, X., Sun, L. and Zhang, X. (2015) A Genetic Coding Variant rs72474224 in GJB2 Is Associated with Clinical Features of Psoriasis Vulgaris in a Chinese Han Population. Tissue Antigens, 86, 134-138. http://dx.doi.org/10.1111/tan.12595

[60] Wu, Y., Lu, Z., Chen, Y., Xue, F., Chen, X., Pan, M. and Zheng, J. (2013) Association of IL-12B Gene rs6887695 Polymorphism with Hereditary Susceptibility and Clinical Characterization of Psoriasis Vulgaris in the Chinese Han Population. Archives of Dermatological Research, 305, 477-482. http://dx.doi.org/10.1007/s00403-013-1342-9

[61] Hebert, H.L., Bowes, J., Smith, R.L., Flynn, E., Parslew, R., Alsharqi, A., McHugh, N.J., Barker, J.N., Griffiths, C.E., Barton, A. and Warren, R.B. (2015) Identification of Loci Associated with Late-Onset Psoriasis Using Dense Genotyping of Immune-Related Regions. British Journal of Dermatology, 172, 933-939. http://dx.doi.org/10.1111/bjd.13340

[62] Allen, M.H., Ameen, H., Veal, C., Evans, J., Ramrakha-Jones, V.S., Marsland, A.M., Burden, A.D., Griffiths, C.E., Trembath, R.C. and Barker, J.N. (2005) The Major Psoriasis Susceptibility Locus PSORS1 Is Not a Risk Factor for Late-Onset Psoriasis. The Journal of Investigative Dermatology, 124, 103-106. http://dx.doi.org/10.1111/j.0022-202X.2004.23511.x

[63] Christensen, T.E., Callis, K.P., Papenfuss, J., Hoffman, M.S., Hansen, C.B., Wong, B., Panko, J.M. and Krueger, G.G. (2006) Observations of Psoriasis in the Absence of Therapeutic Intervention Identifies Two Unappreciated Morphologic Variants, Thin-Plaque and Thick-Plaque Psoriasis, and Their Associated Phenotypes. The Journal of Investigative Dermatology, 126, 2397-2403. http://dx.doi.org/10.1038/sj.jid.5700489

[64] Karabacak, E., Aydin, E., Ozcan, O., Dogan, B., Gultepe, M., Cosar, A. and Muftuoglu, T. (2014) Methylenetetrahydrofolate Reductase (MTHFR) 677C >T Gene Polymorphism as a Possible Factor for Reducing Clinical Severity of Psoriasis. International Journal of Clinical and Experimental Medicine, 7, 697-702.

[65] Baiqiu, W., Songbin, F., Guiyin, Z. and Pu, L. (2000) Study of the Relationship between Psoriasis and the Polymorphic Site C677T of Methylenetetrahydrofolate Reductase. Chinese Medical Sciences Journal, 15, 119-120.

[66] Naldi, L. (2004) Epidemiology of Psoriasis. Current Drug Targets_Inflammation \& Allergy, 3, 121-128. http://dx.doi.org/10.2174/1568010043343958

[67] Yanbaeva, D.G., Dentener, M.A., Creutzberg, E.C., Wesseling, G. and Wouters, E.F. (2007) Systemic Effects of Smoking. Chest, 131, 1557-1566. http://dx.doi.org/10.1378/chest.06-2179

[68] Armstrong, A.W., Harskamp, C.T., Dhillon, J.S. and Armstrong, E.J. (2014) Psoriasis and Smoking: A Systematic Review and Meta-Analysis. British Journal of Dermatology, 170, 304-314. http://dx.doi.org/10.1111/bjd.12670

[69] Sopori, M. (2002) Effects of Cigarette Smoke on the Immune System. Nature Reviews Immunology, 2, 372-377. http://dx.doi.org/10.1038/nri803

[70] McAllister-Sistilli, C.G., Caggiula, A.R., Knopf, S., Rose, C.A., Miller, A.L. and Donny, E.C. (1998) The Effects of Nicotine on the Immune System. Psychoneuroendocrinology, 23, 175-187. http://dx.doi.org/10.1016/S0306-4530(97)00080-2

[71] Armstrong, A.W., Armstrong, E.J., Fuller, E.N., Sockolov, M.E. and Voyles, S.V. (2011) Smoking and Pathogenesis of Psoriasis: A Review of Oxidative, Inflammatory and Genetic Mechanisms. British Journal of Dermatology, 165, 1162-1168. http://dx.doi.org/10.1111/j.1365-2133.2011.10526.x

[72] Malhotra, S. and Mehta, V. (2008) Role of Stressful Life Events in Induction or Exacerbation of Psoriasis and Chronic Urticaria. Indian Journal of Dermatology, Venereology, and Leprology, 74, 594-599. http://dx.doi.org/10.4103/0378-6323.45100

[73] Evers, A., Verhoeven, E., Kraaimaat, F., De Jong, E., De Brouwer, S., Schalkwijk, J., Sweep, F. and Van De Kerkhof, P. (2010) How Stress Gets under the Skin: Cortisol and Stress Reactivity in Psoriasis. British Journal of Dermatology, 163, 986-991. http://dx.doi.org/10.1111/j.1365-2133.2010.09984.x

[74] Kunz-Ebrecht, S.R., Mohamed-Ali, V., Feldman, P.J., Kirschbaum, C. and Steptoe, A. (2003) Cortisol Responses to Mild Psychological Stress Are Inversely Associated with Proinflammatory Cytokines. Brain, Behavior, and Immunity, 17, 373-383. http://dx.doi.org/10.1016/S0889-1591(03)00029-1

[75] Weinstein, G. and Gottlieb, A. (2003) Therapy of Moderate-to-Severe-Psoriasis. CRC Press, Boca Raton.

[76] Sagi, L. and Trau, H. (2011) The Koebner Phenomenon. Clinics in Dermatology, 29, 231-236.

http://dx.doi.org/10.1016/j.clindermatol.2010.09.014 
[77] Balato, N., Di Costanzo, L., Patruno, C., Patri, A. and Ayala, F. (2013) Effect of Weather and Environmental Factors on the Clinical Course of Psoriasis. Occupational and Environmental Medicine, 70, 600. http://dx.doi.org/10.1136/oemed-2013-101505

[78] Fry, L. and Baker, B.S. (2007) Triggering Psoriasis: The Role of Infections and Medications. Clinics in Dermatology, 25, 606-615. http://dx.doi.org/10.1016/j.clindermatol.2007.08.015

[79] Brien, M.O. and Koo, J. (2006) The Mechanism of Lithium and Beta-Blocking Agents in Inducing and Exacerbating Psoriasis. Journal of Drugs in Dermatology, 5, 426-432.

[80] Wolf, R. and Schiavo, A.L. (1997) Is Transglutaminase the Mediator between Antimalarial Drugs and Psoriasis? International Journal of Dermatology, 36, 10-13.

[81] Telfer, N.R., Chalmers, R.J., Whale, K. and Colman, G. (1992) The Role of Streptococcal Infection in the Initiation of Guttate Psoriasis. Archives of Dermatology, 128, 39-42. http://dx.doi.org/10.1001/archderm.1992.01680110049004

[82] Leung, D.Y., Walsh, P., Giorno, R. and Norris, D.A. (1993) A Potential Role for Superantigens in the Pathogenesis of Psoriasis. Journal of Investigative Dermatology, 100, 225-228.

[83] Rajappa, M., Rathika, S., Munisamy, M., Chandrashekar, L. and Thappa, D.M. (2015) Effect of Treatment with Methotrexate and Coal Tar on Adipokine Levels and Indices of Insulin Resistance and Sensitivity in Patients with Psoriasis Vulgaris. Journal of the European Academy of Dermatology and Venereology, 29, 69-76. http://dx.doi.org/10.1111/jdv.12451

[84] Shaharyar, S., Warraich, H., McEvoy, J.W., Oni, E., Ali, S.S., Karim, A., Jamal, O., Blaha, M.J., Blumenthal, R.S., Fialkow, J., Cury, R., Budoff, M.J., Agatston, A.A. and Nasir, K. (2014) Subclinical Cardiovascular Disease in Plaque Psoriasis: Association or Causal Link? Atherosclerosis, 232, 72-78. http://dx.doi.org/10.1016/j.atherosclerosis.2013.10.023

[85] Miller, I.M., Ellervik, C., Yazdanyar, S. and Jemec, G.B. (2013) Meta-Analysis of Psoriasis, Cardiovascular Disease, and Associated Risk Factors. Journal of the American Academy of Dermatology, 69, 1014-1024. http://dx.doi.org/10.1016/j.jaad.2013.06.053

[86] Nijsten, T. and Wakkee, M. (2009) Complexity of the Association between Psoriasis and Comorbidities. The Journal of Investigative Dermatology, 129, 1601-1603. http://dx.doi.org/10.1038/jid.2009.55

[87] Sabat, R., Philipp, S., Höflich, C., Kreutzer, S., Wallace, E., Asadullah, K., Volk, H.D., Sterry, W. and Wolk, K. (2007) Immunopathogenesis of Psoriasis. Experimental Dermatology, 16, 779-798. http://dx.doi.org/10.1111/j.1600-0625.2007.00629.x

[88] Mease, P.J., Signorovitch, J., Yu, A.P., Wu, E.Q., Gupta, S.R., Bao, Y. and Mulani, P.M. (2010) Impact of Adalimumab on Symptoms of Psoriatic Arthritis in Patients with Moderate to Severe Psoriasis: A Pooled Analysis of Randomized Clinical Trials. Dermatology, 220, 1-7. http://dx.doi.org/10.1159/000260371

[89] Gisondi, P., Targher, G., Zoppini, G. and Girolomoni, G. (2009) Non-Alcoholic Fatty Liver Disease in Patients with Chronic Plaque Psoriasis. Journal of Hepatology, 51, 758-764. http://dx.doi.org/10.1016/j.jhep.2009.04.020

[90] Gisondi, P., Cotena, C., Tessari, G. and Girolomoni, G. (2008) Anti-Tumour Necrosis Factor- $\alpha$ Therapy Increases Body Weight in Patients with Chronic Plaque Psoriasis: A Retrospective Cohort Study. Journal of the European Academy of Dermatology and Venereology, 22, 341-344. http://dx.doi.org/10.1111/j.1468-3083.2007.02429.x

[91] Pathirana, D., Ormerod, A.D., Saiag, P., Smith, C., Spuls, P.I., Nast, A., Barker, J., Bos, J.D., Burmester, G.R., Chimenti, S., Dubertret, L., Eberlein, B., Erdmann, R., Ferguson, J., Girolomoni, G., Gisondi, P., Giunta, A., Griffiths, C., Honigsmann, H., Hussain, M., Jobling, R., Karvonen, S.L., Kemeny, L., Kopp, I., Leonardi, C., Maccarone, M., Menter, A., Mrowietz, U., Naldi, L., Nijsten, T., Ortonne, J.P., Orzechowski, H.D., Rantanen, T., Reich, K., Reytan, N., Richards, H., Thio, H.B., van de Kerkhof, P. and Rzany, B. (2009) European S3-Guidelines on the Systemic Treatment of Psoriasis Vulgaris. Journal of the European Academy of Dermatology and Venereology, 23, 1-70. http://dx.doi.org/10.1111/j.1468-3083.2009.03389.x

[92] Saurat, J.H., Stingl, G., Dubertret, L., Papp, K., Langley, R., Ortonne, J.P., Unnebrink, K., Kaul, M. and Camez, A. (2008) Efficacy and Safety Results from the Randomized Controlled Comparative Study of Adalimumab vs. Methotrexate vs. Placebo in Patients with Psoriasis (CHAMPION). British Journal of Dermatology, 158, 558-566. http://dx.doi.org/10.1111/j.1365-2133.2007.08315.x

[93] Strober, B.E. and Menon, K. (2005) Folate Supplementation during Methotrexate Therapy for Patients with Psoriasis. Journal of the American Academy of Dermatology, 53, 652-659. http://dx.doi.org/10.1016/j.jaad.2005.06.036

[94] Gaeta, M., Castelvecchio, S., Ricci, C., Pigatto, P., Pellissero, G. and Cappato, R. (2013) Role of Psoriasis as Independent Predictor of Cardiovascular Disease: A Meta-Regression Analysis. International Journal of Cardiology, 168, 2282-2288. http://dx.doi.org/10.1016/j.ijcard.2013.01.197

[95] Yiu, K.H., Yeung, C.K., Chan, H.T., Wong, R., Tam, S., Lam, K.F., Yan, G., Yue, W., Chan, H. and Tse, H.F. (2011) Increased Arterial Stiffness in Patients with Psoriasis Is Associated with Active Systemic Inflammation. British Jour- 
nal of Dermatology, 164, 514-520. http://dx.doi.org/10.1111/j.1365-2133.2010.10107.x

[96] Kaye, J., Li, L. and Jick, S. (2008) Incidence of Risk Factors for Myocardial Infarction and Other Vascular Diseases in Patients with Psoriasis. British Journal of Dermatology, 159, 895-902. http://dx.doi.org/10.1111/j.1365-2133.2008.08707.x

[97] Ludwig, R.J., Herzog, C., Rostock, A., Ochsendorf, F.R., Zollner, T.M., Thaci, D., Kaufmann, R., Vogl, T. and Boehncke, W.H. (2007) Psoriasis: A Possible Risk Factor for Development of Coronary Artery Calcification. British Journal of Dermatology, 156, 271-276. http://dx.doi.org/10.1111/j.1365-2133.2006.07562.X

[98] Sarwar, A., Shaw, L.J., Shapiro, M.D., Blankstein, R., Hoffman, U., Cury, R.C., Abbara, S., Brady, T.J., Budoff, M.J. and Blumenthal, R.S. (2009) Diagnostic and Prognostic Value of Absence of Coronary Artery Calcification. JACC: Cardiovascular Imaging, 2, 675-688. http://dx.doi.org/10.1016/j.jcmg.2008.12.031

[99] Torres, T., Machado, S., Mendonca, D. and Selores, M. (2014) Cardiovascular Comorbidities in Childhood Psoriasis. European Journal of Dermatology, 24, 229-235.

[100] Groeneveld, M., Huang-Doran, I. and Semple, R. (2012) Adiponectin and Leptin in Human Severe Insulin Resistance-Diagnostic Utility and Biological Insights. Biochimie, 94, 2172-2179. http://dx.doi.org/10.1016/j.biochi.2012.01.021

[101] Bastard, J.P., Maachi, M., Lagathu, C., Kim, M.J., Caron, M., Vidal, H., Capeau, J. and Feve, B. (2006) Recent Advances in the Relationship between Obesity, Inflammation, and Insulin Resistance. European Cytokine Network, 17, 412.

[102] Golden, J.B., McCormick, T.S. and Ward, N.L. (2013) IL-17 in Psoriasis: Implications for Therapy and Cardiovascular Co-Morbidities. Cytokine, 62, 195-201. http://dx.doi.org/10.1016/j.cyto.2013.03.013

[103] Arias-Santiago, S., Orgaz-Molina, J., Castellote-Caballero, L., Arrabal-Polo, M.A., Garcia-Rodriguez, S., Perandres-Lopez, R., Ruiz, J.C., Naranjo-Sintes, R., Zubiaur, M., Sancho, J. and Buendia-Eisman, A. (2012) Atheroma Plaque, Metabolic Syndrome and Inflammation in Patients with Psoriasis. European Journal of Dermatology, 22, 337-344.

[104] Votrubova, J., Juzlova, K., Smerhovsky, Z., Fialova, J., Gopfertova, D., Vojackova, N. and Hercogova, J. (2014) Risk Factors for Comorbidities in Czech Psoriatic Patients: Results of a Hospital-Based Case-Control Study. Biomedical Papers of the Medical Faculty of the University Palacky, 158, 288-294.

[105] Boehncke, W.H., Boehncke, S. and Schon, M.P. (2010) Managing Comorbid Disease in Patients with Psoriasis. BMJ, 340, b5666. http://dx.doi.org/10.1136/bmj.b5666

[106] Alberti, K.G., Zimmet, P. and Shaw, J. (2005) The Metabolic Syndrome-A New Worldwide Definition. The Lancet, 366, 1059-1062. http://dx.doi.org/10.1016/S0140-6736(05)67402-8

[107] Ridker, P.M., Fonseca, F.A., Genest, J., Gotto, A.M., Kastelein, J.J., Khurmi, N.S., Koenig, W., Libby, P., Lorenzatti, A.J. and Nordestgaard, B.G. (2007) Baseline Characteristics of Participants in the JUPITER Trial, a Randomized Placebo-Controlled Primary Prevention Trial of Statin Therapy among Individuals with Low Low-Density Lipoprotein Cholesterol and Elevated High-Sensitivity C-Reactive Protein. The American Journal of Cardiology, 100, 1659-1664. http://dx.doi.org/10.1016/j.amjcard.2007.09.072

[108] Akcali, C., Buyukcelik, B., Kirtak, N. and Inaloz, S. (2014) Clinical and Laboratory Parameters Associated with Metabolic Syndrome in Turkish Patients with Psoriasis. The Journal of International Medical Research, 42, 386-394. http://dx.doi.org/10.1177/0300060513502891

[109] Lowes, M.A., Bowcock, A.M. and Krueger, J.G. (2007) Pathogenesis and Therapy of Psoriasis. Nature, 445, 866-873. http://dx.doi.org/10.1038/nature05663

[110] Anderson, K.S., Petersson, S., Wong, J., Shubbar, E., Lokko, N.N., Carlstrom, M. and Enerback, C. (2010) Elevation of Serum Epidermal Growth Factor and Interleukin 1 Receptor Antagonist in Active Psoriasis Vulgaris. British Journal of Dermatology, 163, 1085-1089. http://dx.doi.org/10.1111/j.1365-2133.2010.09990.x

[111] Gerdes, S., Osadtschy, S., Rostami-Yazdi, M., Buhles, N., Weichenthal, M. and Mrowietz, U. (2012) Leptin, Adiponectin, Visfatin and Retinol-Binding Protein-4-Mediators of Comorbidities in Patients with Psoriasis? Experimental Dermatology, 21, 43-47. http://dx.doi.org/10.1111/j.1600-0625.2011.01402.x

[112] Boehncke, W.H., Boehncke, S., Tobin, A.M. and Kirby, B. (2011) The "Psoriatic March": A Concept of How Severe Psoriasis May Drive Cardiovascular Comorbidity. Experimental Dermatology, 20, 303-307. http://dx.doi.org/10.1111/j.1600-0625.2011.01261.x

[113] Corbetta, S., Angioni, R., Cattaneo, A., Beck-Peccoz, P. and Spada, A. (2006) Effects of Retinoid Therapy on Insulin Sensitivity, Lipid Profile and Circulating Adipocytokines. European Journal of Endocrinology, 154, 83-86. http://dx.doi.org/10.1530/eje.1.02057

[114] Gisondi, P., Cazzaniga, S., Chimenti, S., Giannetti, A., Maccarone, M., Picardo, M., Girolomoni, G. and Naldi, L. (2013) Metabolic Abnormalities Associated with Initiation of Systemic Treatment for Psoriasis: Evidence from the 
Italian Psocare Registry. Journal of the European Academy of Dermatology and Venereology, 27, e30-e41. http://dx.doi.org/10.1111/j.1468-3083.2012.04450.x

[115] Ahmad, Z., Akhtar, S.J., Maan, M.A., Khalid, U. and Hussain, A. (2014) Comparison of Mean Platelet Volume in Patients with Psoriasis and Healthy Individuals. Journal of Pakistan Association of Dermatologists, 24, 1-3.

[116] Saleh, H., Attia, E., Onsy, A., Saad, A. and Abd Ellah, M. (2013) Platelet Activation: A Link between Psoriasis per se and Subclinical Atherosclerosis-A Case-Control Study. British Journal of Dermatology, 169, 68-75. http://dx.doi.org/10.1111/bjd.12285

[117] Davidovici, B.B., Sullivan-Whalen, M.M., Gilleaudeau, P. and Krueger, J.G. (2010) Differing Effect of Systemic Anti Psoriasis Therapies on Platelet Physiology-A Case Report and Review of Literature. BMC Dermatology, 10, 2. http://dx.doi.org/10.1186/1471-5945-10-2

[118] Magen, E., Mishal, J., Zeldin, Y., Feldman, V., Kidon, M., Schlesinger, M. and Sthoeger, Z. (2010) Increased Mean Platelet Volume and C-Reactive Protein Levels in Patients with Chronic Urticaria with a Positive Autologous Serum Skin Test. The American Journal of the Medical Sciences, 339, 504-508. http://dx.doi.org/10.1097/MAJ.0b013e3181db6ed5

[119] Marzano, A.V., Tedeschi, A., Berti, E., Fanoni, D., Crosti, C. and Cugno, M. (2011) Activation of Coagulation in Bullous Pemphigoid and Other Eosinophil-Related Inflammatory Skin Diseases. Clinical and Experimental Immunology, 165, 44-50. http://dx.doi.org/10.1111/j.1365-2249.2011.04391.x

[120] Kölliker Frers, R.A., Bisoendial, R.J., Montoya, S.F., Kerzkerg, E., Castilla, R., Tak, P.P., Milei, J. and Capani, F. (2015) Psoriasis and Cardiovascular Risk: Immune-Mediated Crosstalk between Metabolic, Vascular and Autoimmune Inflammation. IJC Metabolic \& Endocrine, 6, 43-54. http://dx.doi.org/10.1016/j.ijcme.2015.01.005

[121] Gottlieb, A.B. and Dann, F. (2009) Comorbidities in Patients with Psoriasis. The American Journal of Medicine, 122, 1150.e1151-1150.e1159. http://dx.doi.org/10.1016/j.amjmed.2009.06.021

[122] Gelfand, J.M., Shin, D.B., Neimann, A.L., Wang, X., Margolis, D.J. and Troxel, A.B. (2006) The Risk of Lymphoma in Patients with Psoriasis. The Journal of Investigative Dermatology, 126, 2194-2201. http://dx.doi.org/10.1038/sj.jid.5700410

[123] Pouplard, C., Brenaut, E., Horreau, C., Barnetche, T., Misery, L., Richard, M.A., Aractingi, S., Aubin, F., Cribier, B., Joly, P., Jullien, D., Le Maitre, M., Ortonne, J.P. and Paul, C. (2013) Risk of Cancer in Psoriasis: A Systematic Review and Meta-Analysis of Epidemiological Studies. Journal of the European Academy of Dermatology and Venereology, 27, 36-46. http://dx.doi.org/10.1111/jdv.12165

[124] Skudutyte-Rysstad, R., Slevolden, E.M., Hansen, B.F., Sandvik, L. and Preus, H.R. (2014) Association between Moderate to Severe Psoriasis and Periodontitis in a Scandinavian Population. BMC Oral Health, 14, 139. http://dx.doi.org/10.1186/1472-6831-14-139

[125] Chiu, H.Y., Huang, H.L., Li, C.H., Yin, Y.J., Chen, H.A., Hsu, S.T., Lin, S.J., Tsai, T.F. and Ho, S.Y. (2015) Increased Risk of Glomerulonephritis and Chronic Kidney Disease in Relation to the Severity of Psoriasis, Concomitant Medication, and Comorbidity: A Nationwide Population-Based Cohort Study. British Journal of Dermatology, 173, 146-154. http://dx.doi.org/10.1111/bjd.13599 